\title{
Heitor Villa-Lobos, a formação musical da criança e do jovem entre $o$ estético e $o$ ideológico
}

Heitor Villa-Lobos, the musical education for children between the aesthetic and the ideological point of view

\section{$\underline{\underline{\text { Marcos Julio Sergl }}}$}

\section{Maria Auxiliadora Fontana Baseio ${ }^{2}$}

\section{Maria Zilda da Cunha ${ }^{3}$}

1 Pós-Doutor em Comunicações e Doutor em Artes pela Escola de Comunicações e Artes da Universidade de São Paulo. Professor no Programa de Mestrado Interdisciplinar em Ciências Humanas da Universidade Santo Amaro - UNISA, SP. E-mail: mj.sergl@uol.com.br

2 Pós-doutora em Letras pela Universidade do Minho, Braga, Portugal; Doutora em Estudos Comparados de Literaturas de Língua Portuguesa pela Universidade de São Paulo. Professora do Mestrado Interdisciplinar em Ciências Humanas da Universidade de Santo Amaro - UNISA, SP. E-mail: mbaseio@uol.com.br

3 Pós-doutora em Letras pela Universidade do Minho, Braga, Portugal; Pós-Doutora em Ciências, Educação e Humanidades pela UERJ; Doutora em Estudos Comparados de Literaturas de Língua Portuguesa pela Universidade de São Paulo. Professora da Faculdade de Filosofia, Letras e Ciências Humanas da Universidade de São Paulo - Programa de Estudos Comparados de Literaturas de Língua Portuguesa. E-mail: mariazildacunha@hotmail.com. 
RESUMO: É inegável que toda obra de arte reinventa a realidade a partir de um ponto de vista. $\mathrm{O}$ artista recria a partir de categorias de representação reveladoras de uma cosmovisão, amparada por seu imaginário individual, bem como o do seu tempo. Heitor Villa-Lobos foi importante compositor, maestro, violoncelista, pianista, violinista brasileiro do século XX, mundialmente conhecido, embora nunca tenha se enquadrado definitivamente em nenhum movimento cultural específico. Falar desse artista implica investigar duas motivações: a estética e a ideológica. $\mathrm{O}$ objetivo deste artigo, realizado por meio de pesquisa bibliográfica, consiste em discutir a produção artística de Villa-Lobos e sua relação com a formação musical da criança e do jovem.

PALAVRAS-CHAVE: Heitor Villa-Lobos; formação musical para crianças e jovens; estética; ideologia

ABSTRACT: It is undeniable that every work of art reinvents reality from a point of view. The artist recreates based on categories of representation revealing a worldview, supported by his individual imaginary, as well as the imaginary of his time. Heitor Villa-Lobos was an important composer, conductor, cellist, pianist and violinist of the 20th century, world-renowned, although he has never been definitively included in any specific cultural movement. Speaking about this Brazilian artist involves investigating two aspects: aesthetic and ideological motives. This article, carried out through a bibliographical research, aims to discuss the artistic production of Villa-Lobos and its relation with the musical education of the children and the young people.

KEYWORDS: Heitor Villa-Lobos; musical educstion for children and young people; aesthetics; ideology 
Para um início de conversa, é possível generalizar dizendo que a recepção de um evento sonoro implica captura de possibilidades de um fenômeno complexo que, via percepção, abarca qualidades de sentimento, além de mobilizar formas de raciocínio para a intelecção desse fenômeno sensível.

Nessa perspectiva lógica, a linguagem sonora é um sistema semiótico, que compreende dimensões artísticas diferenciadas e possibilidades estéticas multiformes. Assim, a linguagem musical possui, de fato, uma legitimação estética, uma autonomia, como material sonoro nas mais diversas poéticas musicais; deste modo, suas referências podem se voltar para a própria materialidade acústica. Este é o caso da música absoluta. Importa, no entanto, considerar o fato de a semiose sonora projetar-se por contiguidade, e o faz prenhe de signos icônicos, corporificando semelhanças nas qualidades de aparência (imagens), qualidades de movimento e formais (diagramas), bem como promovendo a interação de significados (metáforas). Isto possibilita a consecução de onomatopeias musicais, aspectos da Affektenlebre, da música de programa, da música especulativa e a realização de alusões, de paródias e metalinguagem.

Nessa ordem de ideias, se de fato não se pode perder de vista a importância do aspecto icônico que reverencia a significação musical, impossível é negar a força da contiguidade e dos aspectos indiciais conectados ao contexto cultural, étnico e social. Toda e qualquer obra artística insere-se em relações dinâmicas, funcionando como índice de seu tempo, dos esquemas nocionais de sua cultura e de sua época, engendrando fatores que funcionam significativamente. É assim que se pode afirmar que o nacionalismo, a música engajada e, de certa forma, a música Romântica representaram seus objetos.

Segundo Langer, a música é "um tipo de linguagem não do aqui-agora, mas de conteúdo conceitual genuíno, [como um] símbolo do aspecto irracional da vida mental, da Vontade" (LANGER, 2004, p. 219). Tal chave de interpretação coloca possibilidades estéticas e o desafio das assimilações reflexivas, que emergem nas múltiplas formas de escuta, como questões para reflexão. Isto vale para os compositores ou para teóricos. Nestes termos, a reflexão, a escuta, a produção, a teoria e a materialidade acústica engendram manifestações que vão gerir novos estilos e formas composicionais. A própria escuta torna-se material compositivo.

Gombrich (1986), na clave do visual, diz que o artista não recria o que vê, mas vê o que recria a partir de categorias de representação reveladoras de uma cosmovisão, amparada 
por redes simbólicas que compreendem o imaginário individual do artista, bem como o zeitgeist de seu tempo.

O presente artigo focaliza importante músico brasileiro do século $\mathrm{XX}$, compositor, maestro, violoncelista, pianista, violinista, que chegou a ser mundialmente conhecido, embora nunca tenha se enquadrado definitivamente em nenhum movimento cultural específico. Trata-se de Heitor Villa-Lobos (1887 - 1959).

No intuito de evitar o risco de confundir a dimensão educativa e política que o envolveu com o valor de sua obra artística, tomamos um excerto do texto de Carlos Drummond de Andrade, publicado logo após morte do compositor no Correio da Manhã:

Há tantos falsos grandes, e tantos grandes laboriosos, que só conseguem sê-lo à custa da superposição calculada e teimosa de pedrinhas e sarrafos; em Villa, a grandeza não era apenas autêntica, mas espontânea, inelutável, independia dele, do que ele pretendesse, pensasse ou dissesse; até parecia brigar com o proprietário, às vezes (ANDRADE, 1970 apud SANTOS, 2010, p.132/133).

A mensagem do poeta expressa a forte admiração que detinha por Villa-Lobos e traz um testemunho apaixonado pelo seu vigor artístico. Na esteira de Drummond, este ensaio perspectiva a proeminência do valor do artista.

Na Semana da Arte Moderna, Villa Lobos teve como interlocutor Mário de Andrade, para quem esse carioca era um gênio criador, embora tecnicamente pouco preparado, conforme declara:

O que atrapalha Villa-Lobos é a fantástica falta de organização intelectual. A cabeça dele, cheia de ensinamentos malgeridos, com falhas enormes de instrução, mesmo musical, não lhe permite uma visão estética segura nem do momento, nem da própria obra. É incontestavelmente o mais "genial” de nossos músicos, o que tem invenções mais fortes, mais originais, o de brasilidade mais livre e audaciosa; porém, em geral, o mérito dele se resume a essas invenções. (TONI,1987, p.48) 
Em 1933, Mário de Andrade sente-se pessimista por seu companheiro de luta pelo fato de a renovação das artes dedicar-se ao regime de Vargas.

Falar sobre Villa Lobos implica, portanto, investigar duas motivações: a lúdica e estética, bem como a histórica e ideológica. Eis o objetivo que aqui se apresenta e o qual se busca alcançar por meio de investigação bibliográfica.

O movimento modernista brasileiro reuniu marcas do primitivismo no final da década de 20 do século passado, rebordando o imaginário da terra de maneira muito singular, aliando, no jogo estético, aspectos do mágico e também do ideológico para expressar traços do mundo social, cultural e político do tempo.

A música, assim como outros sistemas semióticos da época modernista, mostra-se visceralmente sintonizada com questões de nossa identidade, tematizando a "nossa terra" e a "nossa gente". O imaginário desse tempo mobiliza desejos, sentidos e ações que pulsam em âmbito coletivo, reorganizando formas de expressão do real, bem como maneiras de transformá-lo criticamente.

Mário de Andrade, com quem Villa-Lobos compartilha amizade e visão de mundo nos períodos iniciais de sua carreira, enuncia, em Pauliceia desvairada, o verso considerado lema do movimento: "Eu sou um índio tupi que toca alaúde". Nesse sentido, o índio selvagem é capaz de entoar sua própria melodia com sons trazidos pelos europeus, ou seja, o Brasil colonizado contempla-se na busca de seu próprio rosto.

No âmago do movimento modernista, poetas, ensaístas, artistas plásticos e músicos compartilhavam o sentimento e o pensamento de que o velho modelo cultural importado do colonizador já não se ajustava aos seus ideais, sendo necessário reconhecer e valorizar, em seus projetos artísticos, a cultura e a identidade nacionais.

Ao perscrutar a forma como Villa Lobos expressa musicalmente os valores sociais e culturais de seu tempo, cumpre analisar um imaginário que reflete temáticas identitárias do contexto. Para tanto, o conceito de textura sonora é fundamental. Ela é resultado do uso de componentes sonoros simultaneamente, a partir da combinação de notas que formam acordes e da escolha dos instrumentos que vão tocar estas notas. Diz respeito a uma "massa sonora verticalmente organizada, que considera, além do parâmetro sonoro correspondente à altura das notas, os demais parâmetros do som: tempo, intensidade e timbre, dentre outros aspec- 
tos" (SPECHT, 2017, p. 23). É habitual compará-la a um tecido: Qual é o material usado? (instrumentos e sonoridades); qual é a densidade dele? (quantos instrumentos são utilizados simultaneamente); qual é a percepção ao manuseá-lo? (duro, leve, macio); qual é a coloração e a estampa? (timbres, ornamentos). A textura musical funciona da mesma forma que a textura do tecido. Ela toca no aspecto sensorial; neste caso, auditivo (SPECHT, 2017).

Villa-Lobos geralmente escolhe texturas densas, com sobreposições sonoras inusitadas para caracterizar o universo tridimensional da floresta. Insere fonemas sem lógica para mostrar códigos linguísticos diferentes dos europeus. "Os processos por onde Villa-Lobos utilizou temas folclóricos ou de inspiração popular em texturas ruidosas seriam como os 'planos sinedóquicos' observados na pintura surrealista ou no cinema" (SALLES, 2009, p. 82) - herança que adveio das vanguardas artísticas do início do século XX.

Uma das obras mais interessantes enquanto textura densa com uma quantidade significativa de camadas sonoras é o Noneto, impressões rápidas de todo o Brasil, composta inicialmente para nove instrumentos, com acréscimos posteriores. Além de diversos instrumentos de percussão, como tam-tam, tambor, pandeiro, xilofone, caixa e o triângulo, Villa-Lobos incluiu instrumentos originais brasileiros, como a puíta ou cuíca (instrumento afro-brasileiro), chocalhos, cocos e um coro indígena com melodias, gritos, ruídos e vocalizes.

No Choros $n^{\circ}$, para coro masculino e sete instrumentos ou para cada uma dessas formações separadamente, Villa-Lobos explora o imaginário a partir de sons onomatopaicos diversos, com melodias Nozani-ná e Ualalôce. Os ostinatos, repetição de determinada frase melódica ou rítmica, reproduzem a noção de tempo cíclico, característica das culturas autóctones.

Da mesma forma, podemos decodificar, em suas estruturas melódicas e harmônicas, sons característicos brasileiros, como do trem maria-fumaça, que percorria o interior de nosso país, e do vento, pelo uso de sons onomatopaicos e usos inusitados de instrumentos da orquestra; a sinuosidade das montanhas, presente na construção de melodias em graus disjuntos; a caudalosidade dos rios, em orquestrações complexas; as vozes dos chorões, na solicitação de performances específicas dos músicos; as línguas dos índios, afrodescendentes e caboclos, pela seleção de palavras sem significado lógico, mas com sonoridades características desses segmentos étnicos. Pela escolha de técnicas instrumentais e vocais específicas, procurou valorizar aspectos de nossa cultura e identidade nacionais. E estas escolhas levaram e levam até hoje o 
ouvinte, seja criança ou adulto, a reminiscências, e, consequentemente, ao reconhecimento de um imaginário brasileiro.

\footnotetext{
Paisagens estas que devem ser entendidas não através e uma leitura materialista e estática de uma feição de um lugar, mas como sendo algo gerador de referências históricas, simbologias e identidades de um grupo. Sendo que assim, a paisagem aqui é entendida [...] como as festas típicas, a culinária, a religião, a música, etc., os símbolos, os traços culturais do grupo (SEVERINO; SOUZA, 2006, p. 15.327).
}

Esses sentimentos e preocupações expressos em seu imaginário advêm de experiências vividas desde criança. Induzido pelo pai, o musicista Raul Villa-Lobos, Heitor estava constantemente ligado aos sons produzidos ao seu redor, seja como curiosidade, seja como parte de seu aprendizado musical.

\footnotetext{
Meu pai, além de ser homem de aprimorada cultura geral e excepcionalmente inteligente, era um músico prático, técnico e perfeito. [...] Aprendi, também, a tocar clarinete e era obrigado a discernir o gênero, estilo, caráter e origem das obras, como declarar com presteza o nome da nota, sons ou ruídos que surgiam incidentalmente no momento, como o guincho da roda de um bonde, o pio de um pássaro, a queda de um objeto de metal, etc. [...] (MARIZ, 1981, p. 104-105).
}

Por Raul Villa-Lobos estar envolvido com a Revolução Federalista do Rio Grande do Sul, foi acusado por Floriano Peixoto de subversivo e teve de fugir com a família para cidades do interior. Primeiramente, Sapucaia, no estado do Rio de Janeiro, e depois, Bicas e Santana dos Cataguases, no estado de Minas Gerais. Essa experiência foi muito rica para Heitor, na ocasião com cinco anos de idade, pois ele pôde conviver com a música sertaneja, pela qual se interessou muito, e vivenciar as brincadeiras e os causos contados pelos locais, fato que abriu sua percepção para o imaginário cultural da terra desde cedo.

Também as viagens realizadas pelo compositor ao longo do Brasil, algumas delas provavelmente fruto de sua imaginação como parte do projeto de ser conhecido como músico 
genuinamente brasileiro, mas, sobretudo, as viagens para os estados de Pernambuco, Bahia e Espírito Santo, percorrendo o interior, pequenas vilas, engenhos e fazendas, influenciaram em sua vertente musical imaginativa.

Villa-Lobos estabelece com sua arte musical um profícuo diálogo com o imaginário infantil de duas maneiras: a) pelo aspecto descritivo dos efeitos sonoros inseridos em suas ambientações para as músicas do repertório autóctone, folclórico e popular brasileiro, já constantes do inconsciente coletivo; e b) pelas diversas formas de aproveitamento de lendas e mitos do folclore brasileiro, em particular do indígena, a partir dos quais ele adapta, cria, ambienta e reaproveita em obras de grande envergadura, como os bailados, as obras sinfônicas, os choros e a música para piano.

Mirelle Borges (2008) destaca o posicionamento de Villa-Lobos no uso da música folclórica.

Villa-Lobos enfatiza os elos existentes entre a sensibilidade infantil, o seu subconsciente e o folclore. Por isso, as crianças deveriam estudar os compositores clássicos, mas principalmente estabelecer contato com a música folclórica, já que tal estilo colocaria a criança em contato com o ritmo. A partir da simplicidade, a criança seria envolvida. As melodias adequadas então seriam as cantigas de ninar, as canções de roda, marchas, etc. A familiaridade das crianças com o folclore advém das características psicológicas raciais, a assimilação das melodias do folclore desencadearia então a percepção das ressonâncias ancestrais (BORGES, 2008, p. 76).

Também observamos a influência do folclore como fator de busca de uma identidade brasileira e de uma paisagem exótica única encontrada em nossas matas e em nossas comunidades interioranas, em obras para instrumentos e em obras sinfônicas e sinfônico-corais. $\mathrm{O}$ próprio Villa-Lobos classificou-as em quatro grupos:

$1^{\circ}$ ) Com influência folclórica indireta: Naufrágio de Kleônicos (I9I 6); Tédio da Alvorada (1917); Uirapuru (1917); Ciclo Brasileiro (1936);

$2^{\circ}$ ) Com alguma influência folclórica direta: Suite de Cânticos Sertanejos (I9og); Danças dos Índios Mestiços (1916); Prole do Bebê no I, Cirandinhas (1926); Lenda do Caboclo (1920); 
$3^{\circ}$ ) Com transfigurada influência folclórica: Série de Choros (I920-I929); Mandú-Çarará (1940); Prole do Bebê $n^{\circ} 2$ (I921); Saudades das Selvas Brasileiras (1927); Três Poemas Indígenas (1926);

$4^{\circ}$ ) Com transfigurada influência folclórica impregnada do universo musical de Bach: Vidapura (I919); Bachianas Brasileiras (1930-1945), entre centenas de outras obras, nas quais busca a criação de uma paisagem sonora característica brasileira, carregando o imaginário nacional por meio de efeitos sonoros diversos. Villa-Lobos também classifica uma quinta categoria, que designa como "em pleno domínio do universalismo" (RIBEIRO, 1987, p. 40-44).

O sistema de composição a partir do decalque do contorno de montanhas e outros acidentes geográficos, denominado música nas montanhas, foi um método de escrita musical de incentivo ao imaginário infantil e à criatividade das crianças. A transposição em papel quadriculado desses contornos, a partir de regras específicas, levava as crianças "a compor" melodias sobre a paisagem observada. A ideia desse sistema foi incentivar a criança a observar mais a paisagem ao seu redor.

A natureza brasileira é vista por Villa-Lobos como um lugar ideal, paradisíaco, por sua monumentalidade e misticismo. Uma parcela significativa de efeitos onomatopaicos utilizados por ele e característicos de toda a sua produção musical são originados de sua escuta na floresta tropical. Ele buscou transportar para sua música a paisagem sonora brasileira ao amalgamar em sua obra o som de pássaros, da fauna, de efeitos sonoros e ruídos de nossas florestas, pois é nelas que estão contadas as diversas lendas indígenas, que pássaros maravilhosos se escondem e que o universo mítico se aloja.

Descartando o sabiá, pássaro que representou a identidade nacional durante o Romantismo literário brasileiro, Villa-Lobos escolheu o uirapuru, pássaro exótico, misterioso e mágico, envolto numa mitologia rica vinculada à cultura indígena e folclórica, muito difícil de ser visto ou ouvido, e que povoava a floresta 'maravilhosa' do Amazonas. [...] Conforme o conhecimento nativo, o uirapuru tem um poder de encantamento sobre os outros pássaros e feras da floresta. Quando ele canta, todas as aves se agrupam ao redor para ouvir o seu canto mavioso (VOLPI, 2009, p. 31). 
O uirapuru é um dos pássaros mais conhecidos do folclore brasileiro, sendo suas penas vistas como amuleto poderoso para obter sorte no amor, no jogo e nos negócios, muito valorizadas no mercado informal das regiões norte e nordeste do país. Richard Spruce (1908) define seu nome "Uirá-purú" como pássaro malhado, de tamanho próximo ao de um pardal. Ele grafou um tema cantado pelo pássaro em sua estada no Amazonas.

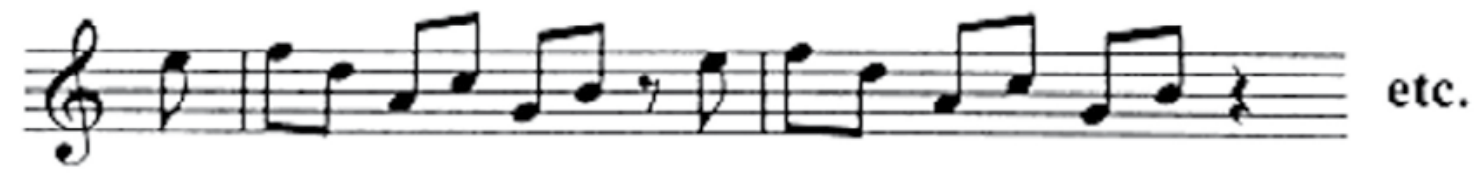

Figura 1. Tema do canto do uirapuru, grafado por Richard Spruce.

Fonte: BRASILIANA, 2009, p. 33.

Villa-Lobos, em seu Bailado Uirapuru (Lenda do pássaro encantado), criou um tema muito próximo ao de Spruce e o desenvolveu como elemento de estruturação de toda a obra. A lenda contada no bailado cita a metamorfose de um índio formoso no pássaro, que, ao ser flechado por uma jovem índia, retoma sua forma humana e, novamente ferido por outro índio, transforma-se em um pássaro invisível. "Revela-se de especial importância o fato de que Villa-Lobos foi o primeiro compositor brasileiro a criar uma lenda que contém padrões míticos indígenas, como a metamorfose" (VOLPI, 2009, p. 35). A metamorfose entre o mundo natural e humano está presente nas narrativas indígenas. Porém, Villa-Lobos foi o primeiro compositor brasileiro a utilizar esta temática e transportá-la para o universo da música de concerto.

A música do Uirapuru está muito próxima da obra Macunaíma, de Mário de Andrade, inclusive pela citação do pássaro. As palavras de Mário de Andrade são transformadas em música por meio de efeitos sonoros, como o som de grilos, sendo realizado pelo piano, em um ostinato rítmico na região mais grave do instrumento e a nota si cinco em stacatto antecedida por uma apogiatura em lá sustenido, e pelo violino na nota sol cinco em fusas intercaladas por pausas. O trecho selecionado do livro nos dá a ideia da importância do pássaro para o escritor. 


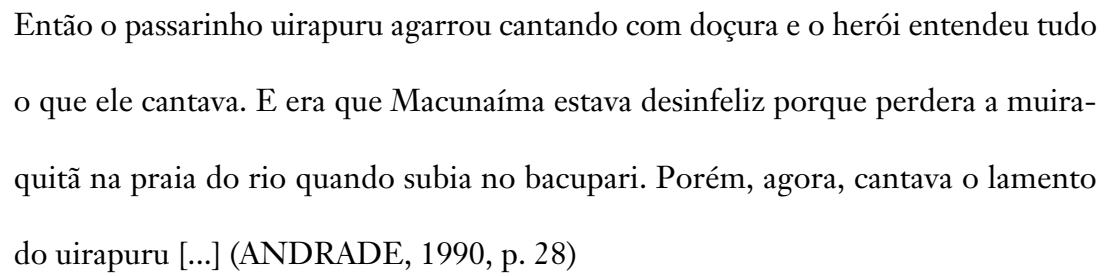

Quanto ao uso de técnicas que possibilitam a imaginação do ouvinte, incluímos o poema sinfônico e bailado Amazonas, pela inclusão do ostinato no piano e nas madeiras para demonstrar o movimento ininterrupto das águas do rio Amazonas e a orquestração ousada para indiciar a densidade e a umidade da floresta. A ousadia no uso da instrumentação, pela junção de instrumentos efetivos da orquestra com instrumentos populares, que indica uma liberdade de expressão, e a pesquisa para encontrar a identidade brasileira; a originalidade, bem como a mescla de técnicas de composição erudita com técnicas da música popular e a utilização de melodias e ritmos indígenas, afrodescendentes e populares fazem de Heitor Villa-Lobos o representante mais significativo do modernismo musical brasileiro do início do século XX.

As transformações que engendram o pensar, sentir e agir de uma cultura estão diretamente articuladas com o imaginário, essa instância que congrega o capital pensado do homo sapiens, conforme afirma Gilbert Durand (1997). Sabe-se estreita a relação entre o imaginário e as artes, de forma a podermos designar a arte musical como linguagem dessa instância imaginativa.

O imaginário nacional engendrou produções estéticas e culturais de nosso país em muitos momentos históricos, sendo marcante no Romantismo - de maneira exótica e ufanista - e no Modernismo - de maneira crítica. Em ambos os momentos culturais, a projeção de uma nova nação brasileira demandava a imaginação de uma nova identidade. O imaginário mítico que Mário de Andrade reinventa em sua obra Macunaíma dialoga com o que Villa Lobos assume como tarefa: ajudar no processo de construção de um projeto nacionalista para o Brasil, propondo revolucionar a linguagem artística a partir de aspectos formais e temáticos.

Portanto, sua linguagem experimentalista, que instaura uma ruptura com a linguagem convencional, funde elementos do universo indígena, africano e europeu, formando um compósito materializador da proposta estética da primeira geração modernista, cujo desígnio era recriar um imaginário da terra brasileira movimentado pelas pulsões de uma nova identidade.

Para tanto, Villa-Lobos foi além da simples compilação da música e da letra. Ele uti- 
lizou diversas técnicas de adaptação e arranjos, que definiu como "ambientações", desde um contraponto sobre uma melodia, até uma polifonia complexa e um acompanhamento que lembra o som do objeto ou ação descrita, em uma busca pelas paisagens sonoras, conceito criado pelo músico canadense Murray Schafer, seja pelo uso de um efeito sonoro, como uma apogiatura ou um trinado, seja pela utilização de sons onomatopaicos.

Acrescenta Alejo Carpentier, que se torna amigo de Villa-Lobos e comenta sua obra em uma série de artigos, entre os quais o da Gaceta Musical, publicado em Paris:

\footnotetext{
E o admirável Tomás Teran se senta ao piano. Executa prestigiosamente uma suíte das Cirandas de Villa-Lobos... E a voz formidável da América, com seus ritmos da selva, suas melodias primitivas, seus contrastes e choques que evocam a infância da humanidade, funde-se ao bochorno da tarde estiva, através de uma música refinadíssima e muito atual. O encantamento surte efeito. Os martelos do piano - baquetas de tambor? - golpeiam mil lianas sonoras, que transmitem ecos do continente virgem. (GUÉRIOS, 2003, p.155 apud NEGWER, 2009, p.163)
}

Seus choros sintetizam diferentes modalidades da música brasileira indígena e popular, o carnaval, as serestas, bem como a música dos índios e dos afro-brasileiros.

Ainda com o intuito de criar uma consciência da identidade nacional brasileira, de fomentar o ensino musical menos rígido que os grupos corais e líricos e de auxiliar na construção do imaginário nacional pelo viés da música, Villa-Lobos, ao voltar da Europa, em 1930, institucionaliza o ensino da música nas escolas brasileiras, por meio do canto orfeônico, designativo de conjuntos vocais, normalmente existentes nas escolas, formados por crianças e jovens (TACUCHIAN, 2009).

O músico acreditava que o canto em grupo seria a resposta musical aos propósitos de Getúlio Vargas relativos à educação como forma de unidade social e disciplinar, típicos de um governo centralizador, conforme suas próprias palavras: "O canto orfeônico é uma das mais altas cristalizações e o verdadeiro apanágio da música, porque, com seu enorme poder de coesão, criando um poderoso organismo coletivo, ele integra o indivíduo no patrimônio social da Pátria.” (VILLA-LOBOS apud RIBEIRO, 1987, p. 90) 
Nesse aspecto, o projeto de canto orfeônico estava alinhado às propostas do governo de buscar e solidificar o "espírito nacional”, fundado nos valores da tradição, da raça, da religião, da língua, das etnias formadoras do povo brasileiro e da memória do passado. A carta enviada por Villa-Lobos em 1932, ao presidente Getúlio Vargas, confirma isto: “[...] eficaz de propaganda, no estrangeiro, sobretudo se for lançada por elementos genuinamente brasileiros, porque desta forma ficará mais gravada a personalidade nacional [...]” (CONTIER, 1998, p. 28).

Villa-Lobos obteve total apoio do governo Vargas e pôde concretizar seu projeto de educação musical, primeiramente no âmbito do espaço físico da capital do país, por meio do Decreto Municipal 4.387, a partir de seu cargo como diretor da Superintendência de Educação Musical e Artística - SEMA, criada por Anísio Teixeira (Secretário do Departamento de Educação da Prefeitura do Rio de Janeiro) em 1932, e depois, em 1938, em nível nacional.

A disciplina de canto orfeônico foi oficialmente reconhecida pelo decreto 19.890, de 18 de abril de 1931, na reforma instituída por Francisco Campos, primeiro ministro da Educação e da Saúde, que definiu a organização do ensino secundário no Brasil. O canto orfeônico foi incluído como disciplina obrigatória do currículo nas três primeiras séries do ensino fundamental.

Esse projeto estava inserido no pensamento de Getúlio Vargas pela busca da ideia de reconstrução nacional, a partir do tripé controle sobre o trabalho, centralização do poder e unidade nacional, e buscava fomentar a disciplina, a educação cívica e a educação artística (VILLA-LOBOS, 1970).

Nada melhor do que uma atividade que unisse crianças e jovens, envolvidos em um projeto aglutinador, o canto em grupo, como forma de propaganda desse pensamento de "Estado forte", participando de apresentações diversas, em particular as festas cívicas, com o objetivo de transmitir os conceitos de "ordem, civismo, unidade nacional e participação coletiva na totalidade da nação" [...] e que "se constituíram como instrumento de legitimação desses símbolos na imaginação coletiva” (TACUCHIAN, 2009, p. 151-152).

É assim que, através de seus imaginários sociais, uma coletividade designa a sua identidade, elabora uma certa representação de si, estabelece a distribuição dos papéis 
e das posições sociais, exprime e impõe crenças comuns, constrói uma espécie de código de 'bom comportamento' [...] (BACZKO,1985, p.309).

Villa-Lobos estava em sintonia com o filósofo John Dewey, que proclamava que a metodologia educacional deveria visar a um fim social e a um fundamento etnológico. A ênfase no canto em grupo na sala de aula, em eventos nas escolas e nas cerimônias cívicas em estádios de futebol com milhares de jovens foi uma das tarefas pedagógicas do compositor brasileiro para atingir estes objetivos.

O canto coletivo, com seu poder de socialização, predispõe o indivíduo a perder no momento necessário a noção egoísta da individualidade excessiva, integrando-o na comunidade, valorizando no seu espírito a ideia da necessidade de renúncia e da disciplina ante os imperativos da coletividade social, favorecendo, em suma, essa noção de solidariedade humana, que requer da criatura uma participação anônima na construção das grandes nacionalidades (VILLA-LOBOS apud RIBEIRO, 1987, p. 87).

Para o compositor, era fundamental trabalhar a memória, a educação cívica, a disciplina e a socialização, a partir de letras e melodias folclóricas, pois elas eram passadas de geração para geração oralmente.

\footnotetext{
Assim, confere-se a elas importante significação cultural e social, pois eram cantigas na língua portuguesa transmitidas com caráter de socialização e ludicidade. Ambas não podem ser separadas, pois a diacronia encontrou a forma na sincronia, constituindo um todo e consequentemente uma identidade da nossa cultura. [...] Os cantos folclóricos criaram vida e circularam por nossa cultura [...] (ROSÁRIO, 2014, p. 38).
}

O canto orfeônico "possibilitou uma prática socializadora, por meio da mobilização de grandes agrupamentos corais", nos quais o participante sentia a integração da coletividade social, em concentrações que reuniam milhares de estudantes, quarenta e dois mil na semana da Pátria de 1940, interpretando músicas do cancioneiro infantil, hinos patrióticos e canções 
ufanistas, além dos chamados "efeitos orfeônicos, reprodução onomatopaica de ruídos naturais, articulados simultaneamente por todo o grupo de cantores", que provocavam verdadeiras catarses coletivas (PAOLIELLO, 2006, p. 154). Conforme Souza,

a tendência de eliminar o sujeito em função do coletivo, numa relação com a música basicamente emocional, resulta numa perigosa direção dos objetivos da música, onde o processo de identificação com a pátria pode ser levado às últimas consequências como a emocionalização dos alunos e sua disposição em morrer pela pátria (SOUZA,1999, p.19).

Essas manifestações públicas, envolvendo a comunidade em geral, segundo o pensamento do governo, promoviam a busca pela identidade e pelo orgulho nacional.

O patrocínio pelo regime varguista de cerimônias cívicas procurava realizar uma síntese cultural em monumentais rituais comemorativos de eventos cívicos e históricos importantes. Estes rituais, que serviram ao propósito múltiplo de unificar elites e massas, também simbolizaram um tempo e um espaço idílico no imaginário político brasileiro. (PARADA, 2009, p. 21).

Carlos Drummond de Andrade deixou um texto emotivo a respeito dessas concentrações, salientando o caráter cívico aglutinador de tais eventos pelo uso de canções ufanistas e de efeitos sonoros que favoreciam o imaginário dos presentes.

A multidão em torno vivia uma emoção brasileira e cósmica, estávamos tão unidos uns aos outros, tão participantes e ao mesmo tempo tão individualizados e ricos de nós mesmos, na plenitude de nossa capacidade sensorial, era tão belo e esmagador, que para muitos não havia outro jeito senão chorar; chorar de pura alegria. Através da cortina de lágrimas, desenhava-se a figura nevoenta do maestro, que captara a essência musical do nosso povo, índios, negros, trabalhadores do eito, seresteiros do arrabalde; que lhe juntara ecos e rumores de rios, encostas, grutas, lavouras, jogos infantis, assobios e risadas de capetas folclóricos (MAIA, 2000, p. 48). 
Anísio Teixeira (1977) deixa clara a busca de Heitor Villa-Lobos por uma sonoridade que levasse os intérpretes e assistentes dessas concentrações a uma emoção coletiva, fundada no imaginário das diferentes paisagens sonoras brasileiras.

\footnotetext{
Quando começaram as grandes exibições públicas, o povo cantou com as crianças e o país assistiu maravilhado e comovido às harmonias de suas florestas, dos grandes ventos dos seus desertos, as melodias dos seus rios e as dores e alegrias das suas diferentes raças, toda a epopeia enfim de um povo, misto e complexo, mergulhado nas extensões tropicais de um continente, posta em som, posta em ritmo, posta em música, numa grande e lírica manifestação de afirmação e grandeza (TEIXEIRA, 1977 , p. 16)
}

Para tornar possível este canto coletivo com qualidade, Villa-Lobos escreveu música simples, despojando-a de elementos mais complexos de linguagem musical, pois a finalidade era pedagógico-doutrinadora, objetivando uma coletividade disciplinada e não a demonstração de técnica refinada. A formação de técnicos musicais virtuoses nunca esteve presente na proposta do projeto de canto orfeônico. Para este fim, foi criada a Escola Nacional de Música.

Para preencher a sua função de música socializadora era necessário, em primeiro lugar, que a música nacional tomasse conhecimento de si mesma pela formação de uma consciência musical brasileira e pela apreensão total do conjunto de fenômenos históricos, sociais e psicológicos, capazes de determinar os seus caracteres étnicos, suas tendências naturais e o seu ambiente próprio [grifo do autor] (VILLA-LOBOS, 1971, p.101-2).

A "formação de uma consciência nacional", fundamentada na ordem, civismo, culto à pátria e ao trabalho, união e exaltação à natureza, foi apoiada metodologicamente por cartilhas e livros didáticos, organizados e/ou compostos por Villa-Lobos em ordem crescente de dificuldade, enfatizando uma educação musical continuada sob a tutela do Estado.

Villa-Lobos, como presidente da SEMA, editou o seguinte material de apoio ao seu 
projeto: Canto Orfeônico, Solfejos e o Guia Prático. A dissertação de mestrado de Marli Batista Ávila, intitulada A Obra Pedagógica de Heitor Villa-Lobos: uma leitura atual de sua contribuição para a educą̧ão musical no Brasil (2010) traz um estudo aprofundado de todas as melodias dos cinco livros de material de apoio reordenados por ordem de dificuldade, com sugestões valiosas de atividades lúdicas, que levam a criança à prática da brincadeira infantil e ao desenvolvimento do imaginário na medida que sugere diversos gestos de imitação de pássaros e de personagens. Muitas dessas atividades lúdicas estavam esboçadas em textos e partituras originais do compositor.

O Canto Orfeônico foi escrito em dois volumes, para diversas formações de vozes, desde uníssono (uma só melodia cantada em conjunto), até arranjos a oito vozes mistas, com ambientações de melodias folclóricas e de canções escritas por músicos e poetas brasileiros. Foi pensado pedagogicamente, pois as ambientações estão dispostas em ordem crescente de dificuldade e constam observações de como podem ser utilizados em sala de aula e acompanhados por performances corporais; dois volumes de Solfejos, com o intuito de incentivar a leitura musical e o Guia Prático.

O Guia Prático, escrito entre 1932 e 1936, composto por cento e trinta e sete peças para coro infantil e infanto-juvenil em sua primeira parte, com arranjos e harmonizações em diversos níveis de dificuldade, foi o material didático utilizado em todas as escolas brasileiras nesse período. Foi pensado para servir de auxílio às atividades dos professores de música, visando à educação cívico-social, à formação do gosto artístico e à construção de um imaginário social. (VILLA-LOBOS, 1941)

Segundo Villa-Lobos, deveria ter seis volumes, divididos em: $1^{\circ}$ ) canções infantis; $2^{\circ}$ ) canções cívicas; $3^{\circ}$ ) canções nacionais e estrangeiras; $4^{\circ}$ ) temas ameríndios e canções afro-brasileiras; $5^{\circ}$ ) música universal; $6^{\circ}$ ) coletânea de peças eruditas. Até hoje, apenas o primeiro volume foi encontrado.

Representou um instrumento de trabalho para os músicos que, na época estavam engajados no movimento do Canto Orfeônico, liderado pelo próprio Villa-Lobos, e que foi o mais importante projeto de educação musical implementado no país até nossos dias. (TACUCHIAN, 2009, p. 8) 
A busca de um repertório significativo, já presente no inconsciente coletivo das crianças e jovens, influiu "na legitimação desse mesmo imaginário", e a utilização do folclore, com sua função socializadora, na fixação dele.

Para o compositor, era por meio do folclore que se chegaria a uma "consciência musical brasileira", pela apreciação de uma música "verdadeiramente artística” (VILLA-LOBOS, 1971, p. 126), pensamento coincidente com a ideia da construção do "Brasil Novo", a partir da Revolução de 1930, que proclamava o folclore como "as falas das camadas subalternas da sociedade", sendo o sertão a fonte autêntica da brasilidade (BORGES, 2008, p. 82).

Tendo o folclore como referência, o compositor educador sintetizou seu pensamento e sua prática pedagógica nesse trabalho, que, conforme afirmou o compositor Edino Krieger (1974, p. 60) '[se apresenta] como reflexo simultâneo de duas entidades culturais: de um lado o folclore, de outro, o artista criador que dele se utiliza' (PAOLIELLO, 2006, p. 155).

Villa-Lobos tinha consciência de sua relevância na mudança histórico-cultural do início do século, bem como do papel da educação musical na formação das crianças e jovens.

O imaginário que expressa traduz aspirações estéticas e também ideológicas. A despeito de associar-se, em determinado momento, à ideologia política, não é desprezível a força mágica da alma brasileira em todas as partituras nas quais a corporifica.

O trabalho de Villa-Lobos destaca-se até hoje como exemplo de autodescoberta musical não apenas do Brasil, mas também da América Latina. Diferente de seus contemporâneos sul-americanos, contrariou a hegemônica herança musical europeia, valorizando sua pátria em seus aspectos físicos, culturais e humanos, imprimindo, em sua obra, a força mágica, as melodias e ritmos de nosso povo. Villa-Lobos cria um imaginário musical que expressa a alma do povo brasileiro.

O “embaixador cultural do Brasil”, de vanguardista a funcionário da música, após a Era Vargas, retoma suas atividades com a proposta de uma síntese entre o velho e o novo, entre o genuíno e o universal.

Sabemos que o tecido artístico abriga movimentos hermenêuticos potencializadores de leituras plurais. Entretanto, não há como negar que Villa-Lobos exercita uma paradoxal conciliação entre o efêmero e o eterno, o que eleva sua obra à qualidade de arte. 


\section{Referências}

ANDRADE, Mário. Macunaíma: o herói sem nenhum caráter. Rev. Telê Porto Ancona Lopez. 26 ed. Belo Horizonte: Villa Rica Editoras Reunidas, 1990.

ÁVILA, Marli Batista. A Obra Pedagógica de Heitor Villa-Lobos: Uma leitura atual de sua contribuição para a educação musical no Brasil. Tese de Doutorado em Artes. São Paulo: Universidade de São Paulo, 2010.

BACZKO, Bronislaw. Imaginação social. Enciclopédia Einaudi. (Antropos-Homem, 5). Lisboa: Imprensa oficial; Casa da Moeda; Ed. Portuguesa, 1985.

BORGES, Mirelle Ferreira. Heitor Villa-Lobos, o músico educador. Dissertação de Mestrado em História. Niterói: Universidade Federal Fluminense, 2008.

CONTIER, Arnaldo Daraya. Passarinhada do Brasil: canto orfeônico, educação e getulismo. São Paulo: Edusc, 1998.

KRIEGER, Edino. O Guia Prático de Villa-Lobos. Presença de Villa-Lobos, Rio de Janeiro: MEC/ Museu Villa-Lobos, n. 9, 1974.

LANGER S. K. Filosofia em nova chave. São Paulo: Editora Perspectiva, 2004.

GOMBRICH, E. Arte e Ilusão. São Paulo: Martins Fontes, 1986.

MAIA, Maria. Villa-Lobos: alma brasileira. Rio de Janeiro: Contraponto: Petrobrás, 2000.

MARIZ, Vasco. História da Música no Brasil. Rio de Janeiro: Civilização Brasileira / INL MEC, 1981. 
NEGWER, Manuel. Villa-Lobos: o florescimento da música brasileira. São Paulo: Martins Fontes,2009.

PAOLIELLO, Guilherme. Villa-Lobos e o canto coletivo na Era Vargas. Artefilosofia. N. 1. Julho de 2006. P. 151-159. Ouro Preto: UFOP, 2006.

PARADA, Maurício. Educando Corpos e Criando a nação: Cerimônias cívicas e práticas disciplinares no Estado Novo. Rio de Janeiro: Ed. PUC Rio: Apicuri, 2009.

RIBEIRO, João Carlos (org.). O pensamento vivo de Heitor Villa-Lobos. São Paulo: Martin Claret, 1987. (Coleção Pensamento Vivo 8).

ROSÁRIO, Ana Cláudia Trevisan Rosário. Refletindo sobre as cartas sem resposta de Heitor Villa-Lobos: Filosofia e Semiótica na criação Villa-lobiana. Dissertação de Mestrado em Filosofia. Pontifícia Universidade Católica de São Paulo. 2014.

SALLES, Paulo de Tarso. Villa-Lobos: processos composicionais. São Paulo: Unicamp, 2009.

SANTOS, Marco Antonio Carvalho. Heitor Villa-Lobos. Recife: Fundação Joaquim Nabuco, Editora Massangana, 2010.

SEVERINO, Cláudio Francisco; SOUZA, Fernando Lucci Resende de. Heitor Villa-Lobos e o uso da representação simbólica da diversidade territorial brasileira na música erudita. Anais do X Encontro de Geógrafos da América Latina. São Paulo: Universidade de São Paulo, 2006, p. 15319-15336.

SOUZA, Jusamara. A concepção de Villa-Lobos sobre educação musical. Revista Brasiliana. Edição especial. Rio de Janeiro: Academia Brasileira de Música. n. 3, p.18-25, set. 1999.

SPECHT, Roberta. Heitor Villa-Lobos: por uma narrativa musical da nação. Dissertação de 
Mestrado em História. Santa Maria: Universidade Federal de Santa Maria, 2017.

SPRUCE, Richard. Notes of a Botanist on the Amazonas \& Andes. Vol. 1. Londres: Macmillan and Co., Limited, 1908.

TACUCHIAN, Ricardo. Villa-Lobos, uma revisão. Revista Brasiliana. Rio de Janeiro: Academia Brasileira de Música, n. 29, p. 05-14, ag. 2009.

TEIXEIRA, Anísio. Villa-Lobos. In: Presença de Villa-Lobos. $1^{\circ}$ Volume. Rio de Janeiro: Museu Villa-Lobos, 1977.

TONI, Flávia Camargo. Mário de Andrade e Villa-Lobos. Revista do Instituto de Estudos Brasileiros. São Paulo: USP, n.27, 1987.

VILLA-LOBOS, Heitor. Guia prático: estudo folclórico musical. São Paulo / Rio de Janeiro: Irmãos Vitale, 1941.

Educação musical. Presença de Villa-Lobos, Rio de Janeiro: MEC/ Museu Villa-Lobos, n. $6,1971$.

. A educação artística no civismo. Presença de Villa-Lobos, Rio de Janeiro: MEC/ Museu Villa-Lobos, n.5, 1970.

VOLPI, Maria Alice. Villa-Lobos e o Imaginário Edênico de Uirapuru. Revista Brasiliana. Rio de Janeiro: Academia Brasileira de Música, n. 29, p. 29-34, ag. 2009. 